\title{
The restricted hospital order
}

\author{
Graham Robertson, Lecturer in Forensic Psychiatry, Institute of Psychiatry, \\ De Crespigny Park, London SE5
}

Under the 1959 Mental Health Act of England and Wales, it was possible for courts to sentence offenders to hospital provided they had been found guilty of an offence which was punishable by a term of imprisonment. Higher courts could add restrictions to a hospital order if they so wished. This power has been retained in the 1983 Mental Health Act and this paper examines the nature and use of the restricted hospital order.

\section{Genesis and development of the restricted order}

The Royal Commission on the Law relating to Mental Illness and Mental Deficiency 1954-1957 (The Percy Commission) ${ }^{1}$ recommended to Parliament that the power to discharge certain offender patients should reside with the Home Secretary: “. . . we think it desirable that the discharge of patients admitted following court proceedings who are known to be dangerous should be controlled by a central authority who would have special regard to the protection of the public.

We therefore recommend that in cases in which the court is satisfied that an offender requires medical care, treatment or training but that there is a real danger of the commission of further serious offences if he is discharged prematurely, it should be possible for (higher courts), but not magistrates courts, to name a period within which he should not be set at large without the consent of the Home Secretary" (paras. 518 and 519).

The term 'prematurely' was not elaborated on in the report but it must be assumed that the restriction order was designed "to protect the public against the over optimism or irresponsibility of psychiatrists". 2 (p.90). After all, the reforms proposed by the Commission centred on the need for restricting the liberty of the mentally disordered only when harm to the patients themselves or to others was considered likely. With proper provision for independent review, the power to detain was to be vested in members of the medical profession. In suggesting that courts give this power to someone outside the medical profession, the Commission was indicating the need for courts to be able to prevent a dangerous act by the doctor, not the prospective patient.
This could not be stated in so many words, and so, with draftsman's skill, the justification for restriction was held to be due to the offender's characteristics and its implementation was justified in parliamentary debate on the Bill with reference to the advantages conferred by the restriction order's after care provisions. $^{2}$ (p. 90). These allow for restricted patients to be discharged on condition, for example, that they live at a certain address and attend outpatient clinics on a regular basis. It also provides the facility for immediate recall of patients to hospital should there be a deterioration in mental state.

The restriction order was to be made in consideration of criminal rather than psychiatric criteria. Section 65(1) of the 1959 Mental Health Act stated: "When a hospital order is made (...) and it appears to the court, having regard to the nature of the offence, the antecedents of the offender and the risk of his committing further offences if set at large, that it is necessary for the protection of the public so to do, the court may (...) further order that the offender shall be subject to the special restrictions set out in this section, either without limit of time or during such period as may be specified in the order".

The special conditions imposed were quite drastic, denying the right of the patient to be discharged by appeal to a Mental Health Review Tribunal (MHRT) and ordering that even leave of absence from the hospital could not be granted without the consent of the Secretary of State (Section 65(3) (c) (i)).

The Commission" ${ }^{1}$ felt it "important that compulsory powers should not be kept in force for any patient when detention in hospital or control under guardianship can no longer be justified on the grounds set out in paragraph 317 (of their report)" (para. 527). This set out the conditions in which the Commission considered the use of detention to be justified, regardless of whether or not an offence had been committed. In essence, these were that the person required treatment which could not be provided without the use of compulsory powers and that either such treatment offered likely benefit or that there was "a strong need to protect others from anti-social behaviour by the patient". The Commission concluded that "There should therefore be ample opportunities for reviewing the medical diagnosis, the prospect of 
benefit to the patient from the treatment he is receiving or (in regard to those detained in hospital) the need to segregate the patient from the community for the protection of the public" (para. 527).

It would seem the Commission regarded mental institutions as secure. Hospital order disposals could only be made in respect of imprisonable offences for this reason. The notion that detention in a mental hospital could be equated with detention in prison in this respect permeates the report and dominates the debate surrounding the issue of whether and what time limits should be imposed on restriction orders (paras 527-534). This premise, and the fact that it became untenable once the 1959 Act had been implemented has formed the basis for many of the problems surrounding the use of restriction orders in local hospitals. ${ }^{2,3}$

The reasoning of the Commission in the matter of restricted orders is difficult to follow. At every point, it was maintained in the Percy Report that the requirements concerning the detention of the offender patient should not differ from those of the patient under civil detention, yet at the same time it was proposed that, in certain circumstances, the former be made subject to Home Office control.

In the 1983 Act, the wording of the order was altered slightly and the power to order the discharge of restricted patients has been given to Mental Health Review Tribunals as well as to the Home Secretary. In the case of restricted patients, such Tribunals must be chaired by a circuit judge or a silk recorder and restricted patients are now able to apply to a Tribunal six months after admission to hospital and thereafter on a yearly basis. ${ }^{4}$ This amendment was introduced relatively late in the reform of the 1959 Act. The Review of the Mental Health Act 1959 , presented to Parliament in 1978, contained no reference to the prospect of Tribunals being given the power to discharge restricted patients (The Review of the Mental Health Act 1959, paras 6.9-6.13). ${ }^{3}$ As outlined in a Joint DHSS/Home Office consultative document, ${ }^{4}$ the change "stemmed from the judgment in 1981 of the European Court of Human Rights in the case of ' $X$ v UK'. The Court finding was not concerned with who should be detained, or for how long, but with what it held to be a breach of Article 5(4) of the European Convention on Human Rights in detaining a patient in hospital without giving him proper access to a judicial body which could speedily review the lawfulness of his detention and, if necessary, order his discharge, (...) the conclusion was that strengthened tribunals offered the best approach".

A Mental Health Review Tribunal is obliged to order the absolute discharge of a restricted patient if it is satisfied "that he is not then suffering from (mental disorder) which makes it appropriate for him to be liable to be detained in a hospital for medical treatment; or that it is not necessary for the health or safety of the patient or the protection of other persons that he should receive such treatment". (MHA 1983 Section 73(a)). The conditions set down in the first clause make it plain that detention in a hospital for medical treatment must be made on some judgment of the nature or degree of disorder present. The terms used are imprecise, but it may be argued that the degree of disorder which in practice warrants detention under the civil powers of the Act provide a guide to those responsible for ordering the continued psychiatric detention of the restricted patient.

For psychiatric detention to take place under the civil powers of the Mental Health Act, two conditions must be met. Firstly, disorder must be present and secondly, harm to the patient or others considered likely. That part of the Act concerned with offender patients and under which all restricted patients are admitted to hospital requires only that the first of these conditions apply, namely that disorder be established. In effect, the fact that the person concerned has been convicted of an offence replaces the likely harm clause required for civil detention. The validity of this equation is highly questionable but it would be possible for the members of a Tribunal to judge the merits of a patient's post trial detention on the criteria laid down for civil patients if they wished to do so.

\section{The restriction order in practice}

The numbers of restricted hospital orders made annually since 1961 are shown in Table I and are graphically represented in Fig. 1. The top line of the figure presents the total number of such orders and the other lines the number of orders made to special hospitals, which are managed by the DHSS, and to local psychiatric hospitals. As is clear from the Figure, the number of restriction orders made by courts rose fairly steadily during the first ten years of the Act's operation, from around 150 in the early 1960 s to 250 orders per year in the early 1970 s. The period since 1973 has witnessed a decline in use, so that in the last three years for which figures are available, between 100 and 120 restriction orders have been made each year for the whole of England and Wales. The implementation of the 1983 Mental Health Act brought about a rise in the number of unrestricted hospital orders being made (see Table II), but no similar, 'new Act' effect is apparent for restricted orders.

\section{(a) By type of hospital}

The distribution of orders between local and special hospitals was fairly even until 1970. In each year since then, special hospitals have accounted for more than half restricted patient admissions. The number of beds and the admission practices of the two types 
TABLE I

Restricted hospital orders from 1961 to 1985

\begin{tabular}{|c|c|c|c|c|c|c|c|c|c|c|}
\hline \multirow[b]{2}{*}{ Year } & \multirow[b]{2}{*}{ Total } & \multicolumn{3}{|c|}{ By disorder* } & \multicolumn{2}{|c|}{ By sex } & \multicolumn{4}{|c|}{ By type of offence } \\
\hline & & $M I$ & $S N$ & $P D$ & $M$ & $F$ & violence & theft & $\operatorname{sex}$ & other ${ }^{* *}$ \\
\hline 1961 & 154 & 63 & 56 & 25 & 137 & 17 & 62 & 53 & 34 & 14 \\
\hline 1962 & 138 & 56 & 37 & 33 & 127 & 11 & 60 & 33 & 28 & 17 \\
\hline 1963 & 159 & 85 & 42 & 33 & 147 & 12 & 66 & 43 & 34 & 16 \\
\hline 1964 & 185 & 104 & 30 & 45 & 173 & 12 & 74 & 35 & 31 & 45 \\
\hline 1965 & 196 & 100 & 59 & 34 & 178 & 18 & 72 & 58 & 30 & 36 \\
\hline 1966 & 180 & 84 & 59 & 36 & 166 & 14 & 67 & 46 & 35 & 32 \\
\hline 1967 & 271 & 137 & 62 & 70 & 246 & 25 & 113 & 59 & 42 & 57 \\
\hline 1968 & 255 & 130 & 55 & 67 & 233 & 22 & 109 & 44 & 25 & 77 \\
\hline 1969 & 254 & 124 & 61 & 66 & 224 & 30 & 104 & 71 & 45 & 34 \\
\hline 1970 & 278 & 132 & 67 & 75 & 262 & 16 & 113 & 59 & 53 & 53 \\
\hline 1971 & 232 & 97 & 50 & 83 & 213 & 19 & 115 & 47 & 22 & 48 \\
\hline 1972 & 212 & 108 & 31 & 73 & 197 & 15 & 99 & 45 & 37 & 31 \\
\hline 1973 & 266 & 124 & 44 & 95 & 245 & 21 & 94 & 55 & 59 & 58 \\
\hline 1974 & 196 & 93 & 22 & 79 & 176 & 20 & 94 & 18 & 30 & 54 \\
\hline 1975 & 156 & 81 & 18 & 56 & 132 & 24 & 68 & 13 & 22 & 53 \\
\hline 1976 & 151 & 84 & 22 & 44 & 125 & 26 & 84 & 16 & 29 & 22 \\
\hline 1977 & 90 & 49 & 7 & 32 & 76 & 14 & 51 & 10 & 6 & 23 \\
\hline 1978 & 127 & 81 & 13 & 33 & 113 & 14 & 68 & 6 & 15 & 48 \\
\hline 1979 & 102 & 78 & 7 & 17 & 84 & 18 & 58 & 12 & 5 & 27 \\
\hline 1980 & 118 & 82 & 9 & 28 & 93 & 26 & 70 & 12 & 7 & 29 \\
\hline 1981 & 107 & 65 & 10 & 30 & 87 & 20 & 61 & 6 & 4 & 36 \\
\hline 1982 & 143 & 102 & 8 & 39 & 126 & 16 & 92 & 10 & 7 & 34 \\
\hline 1983 & 120 & 85 & 12 & 18 & 104 & 16 & & & & \\
\hline 1984 & 110 & 78 & 9 & 23 & & & & & & \\
\hline 1985 & 114 & 76 & 9 & 23 & & & & & & \\
\hline
\end{tabular}

* These figures do not include the small number of people given orders under more than one legal category.

** Details are unavailable because of changes in the practice of recording offences but many of the 'other' offences are of arson.

of hospital differ greatly; the proportion of admissions to special hospitals accounted for by restricted patients in 1985 for example was $30 \%(64 / 210)$ whereas that to local hospitals was negligible, $0.02 \%$ $(50 / 23,7795)$. After 1973 , there was a marked decrease in the admission of restricted patients to both types of hospital and this decline may be related to the immense amount of publicity which accompanied the case of a former Broadmoor patient. The man concerned had been admitted to that hospital under a restriction order in 1962 following conviction for attempts to poison members of his family. He was conditionally discharged in 1971 and later convicted of murdering several of his colleagues at work by poisoning them. The case led to the setting up of a committee of enquiry (The Aarvold Committee) into the discharge and supervision of restricted patients. ${ }^{6}$

Whether it also led directly to the declining use of the order cannot be established, but the case generated a great deal of adverse publicity and may have acted as the 'last straw' for long-standing discontent about restricted order patients in local hospitals.
Certainly the intake of restricted patients to local psychiatric hospitals, which had remained at a fairly constant level over the 12 years prior to 1973 , decreased rapidly to fewer that 30 orders by 1977 . The restriction order has been unpopular with local hospital consultants as it places a considerable administrative burden on them and limits their authority to make relatively simple decisions about the patient's management. The so called open door policy operated by the majority of local hospitals rendered the notion of secure containment a nonsense. ${ }^{2.7}$

\section{(b) By type of disorder}

Hospital orders with restriction have constituted, on average, $16 \%$ (s.d. 3.4) of all hospital orders. The proportion rose to an average of $20 \%$ (s.d. 2.3) between 1967 and 1974 , but fell to around $15 \%$ from 1980 onwards (Tables I and II).

Orders under the legal category of Psychopathic Disorder (PD) have comprised, on average, $26 \%$ (s.d. 7.1) of all restricted orders made annually, a 


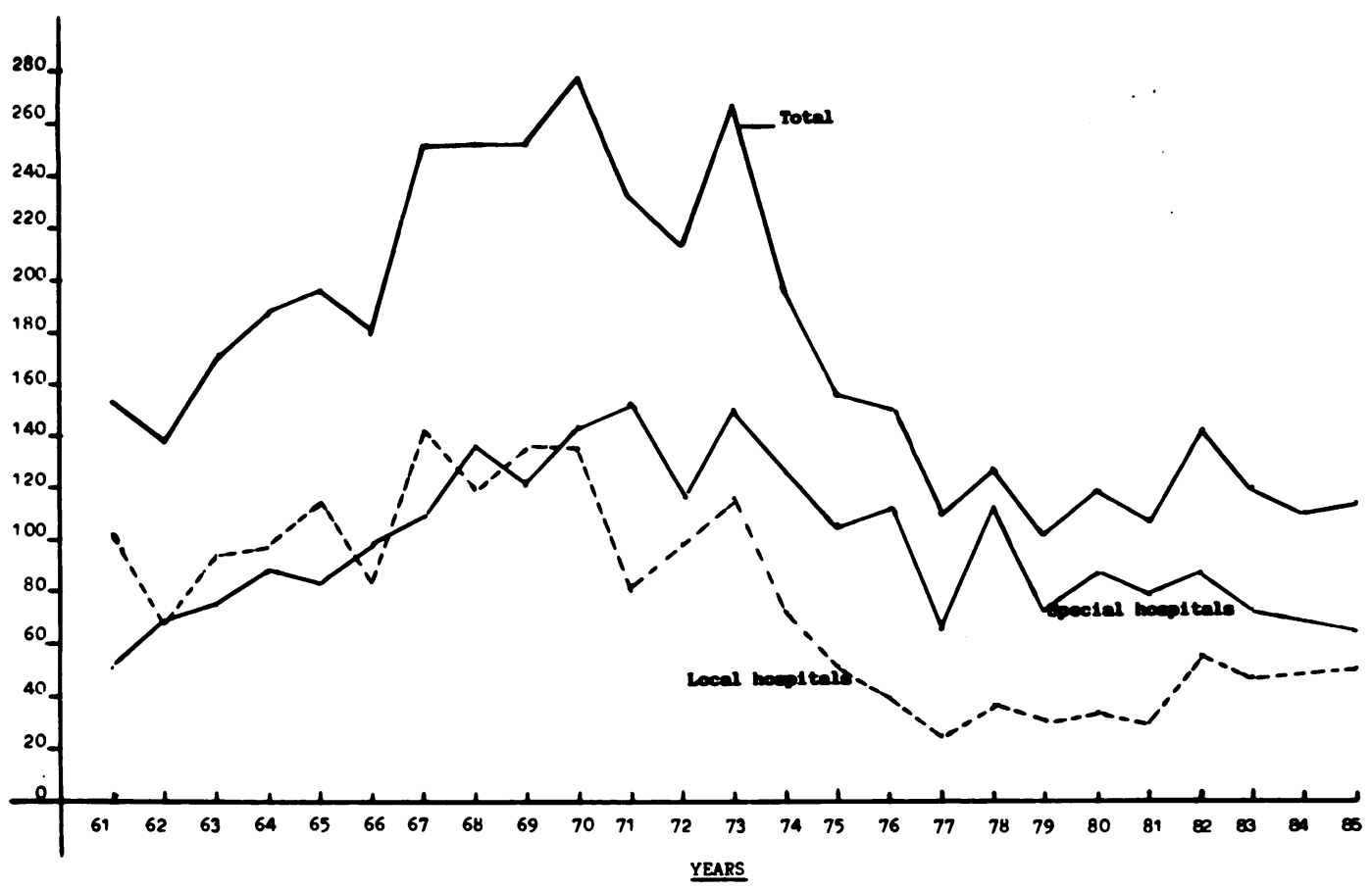

Fig. 1. Restriction orders since 1961 by type of hospital

significantly higher proportion than for unrestricted orders, where the PD category accounts for an average of only $5.5 \%$ (s.d. 1.8) of orders made over the same period $(P<.0001)$. The proportion of unrestricted orders under the PD category has been remarkably constant over the years (see the relevant standard deviation). This consistency contrasts with the many fluctuations present in the equivalent statistics for the restricted population so that there is no correlation between the two sets of figures $(r=.006)$. As a proportion of all PD orders made annually, restricted orders account for $47 \%$ on average (s.d. 11.8), a figure far in excess of the other legal categories specified in the legislation, the equivalent figure for mental illness (MI) being $12.6 \%$ and for the mentally handicapped, 15\% (mentally handicapped people are referred to as subnormal (SN) in the 1959 Act and as mentally impaired in the 1983 Act, though this latter term also includes behavioural criteria).

The number of restricted hospital orders made in respect of people who are mentally handicapped declined after 1970, in parallel with unrestricted orders for this group $(r=0.93 P<0.0001)$. The average number of 32 orders per year is not meaningful given the very large standard deviation (s.d. 21.6) and since 1978 , the annual raw number of such orders has rarely reached double figures. Expressed as a percentage of all orders within this category of mental disorder, restricted orders have averaged $15 \%$ (s.d. 4.3), significantly fewer than in the psychopathic group $(P<0.0001)$ but somewhat higher than the equivalent proportion for mentally ill offenders $(P<0.05)$.

Because of the decline in the number of restricted orders for mental handicap, the proportion of such orders accounted for by the legal category of mental illness has increased over the years, from a mean proportion of $49 \%$ (s.d. 4.5 ) in the period 1961 to 1970 , to a mean of $69 \%$ (s.d. 4.6) in the years from 1979 to $1985(P<0.0001)$. However, the actual numbers of orders made during those years has fallen, from an average of 101 to 81 , though this is not statistically significant due to the large variations within the distributions. The mean number of restricted orders made under the mental illness category is 91.9 (s.d. 31.9), and the mean proportion, $56 \%$ (s.d. 9.3). Expressed as a proportion of all hospital orders per year under mental illness, restricted orders account for only $12.6 \%$ on average (s.d. 2.83 ), a significantly smaller proportion than that obtaining in the PD category $(P<0.0001)$

\section{(c) By sex}

Table I contains details of restricted orders by sex (figures are only available to 1983). The raw number of females given restricted orders varies little, from 11 
TABLE II

Unrestricted hospital orders from 1961 to 1985

\begin{tabular}{|c|c|c|c|c|c|c|c|c|c|c|}
\hline \multirow[b]{2}{*}{ Year } & \multirow[b]{2}{*}{ Total } & \multicolumn{3}{|c|}{ By disorder* } & \multicolumn{2}{|c|}{ By sex } & \multicolumn{4}{|c|}{ By type of offence ${ }^{* *}$} \\
\hline & & $M I$ & $S N$ & $P D$ & $M$ & $F$ & violence & theft & $\operatorname{sex}$ & other \\
\hline 1961 & 912 & 439 & 387 & 58 & 739 & 173 & 115 & 449 & 134 & 185 \\
\hline 1962 & 1035 & 553 & 383 & 59 & 834 & 201 & 121 & 438 & 135 & 209 \\
\hline 1963 & 1068 & 614 & 400 & 45 & 847 & 221 & 130 & 562 & 132 & 223 \\
\hline 1964 & 1173 & 626 & 466 & 74 & 991 & 182 & 134 & 610 & 164 & 225 \\
\hline 1965 & 1084 & 617 & 404 & 77 & 939 & 145 & 146 & 512 & 176 & 231 \\
\hline 1966 & 1257 & 690 & 444 & 120 & 1088 & 169 & 170 & 669 & 160 & 210 \\
\hline 1967 & 1150 & 651 & 410 & 83 & 992 & 158 & 129 & 589 & 155 & 239 \\
\hline 1968 & 1127 & 667 & 380 & 87 & 953 & 174 & 165 & 435 & 176 & 261 \\
\hline 1969 & 1097 & 662 & 341 & 87 & 946 & 151 & 144 & 598 & 122 & 191 \\
\hline 1970 & 1039 & 680 & 278 & 63 & 890 & 149 & 163 & 525 & 124 & 221 \\
\hline 1971 & 953 & 666 & 210 & 69 & 839 & 114 & 129 & 460 & 113 & 238 \\
\hline 1972 & 832 & 601 & 164 & 57 & 710 & 122 & 174 & 428 & 104 & 125 \\
\hline $1973^{* * * *}$ & 888 & 665 & 161 & 62 & - & - & 124 & 390 & 45 & 315 \\
\hline 1974 & 808 & 737 & 120 & 46 & - & - & 124 & 320 & 44 & 320 \\
\hline 1975 & 861 & 695 & 94 & 40 & 729 & 132 & 153 & 346 & 43 & 319 \\
\hline 1976 & 773 & 644 & 40 & 23 & 641 & 132 & 127 & 480 & 33 & 127 \\
\hline 1977 & 831 & 616 & 33 & 29 & 623 & 108 & 140 & 270 & 32 & 299 \\
\hline 1978 & 682 & 586 & 63 & 28 & 571 & 111 & 124 & 238 & 20 & 300 \\
\hline 1979 & 657 & 557 & 63 & 27 & 514 & 143 & 142 & 227 & 29 & 259 \\
\hline 1980 & 689 & 614 & 41 & 23 & 546 & 143 & 170 & 242 & 37 & 341 \\
\hline 1981 & 681 & 596 & 37 & 26 & 559 & 122 & 138 & 218 & 27 & 283 \\
\hline 1982 & 612 & 524 & 46 & 27 & 503 & 109 & 164 & 186 & 26 & 234 \\
\hline 1983 & 733 & 661 & 39 & 33 & 606 & 127 & 190 & 213 & 33 & 297 \\
\hline 1984 & 819 & 764 & 41 & 14 & 686 & 133 & 253 & 241 & 31 & 283 \\
\hline 1985 & - & 655 & 39 & 43 & & & & & & \\
\hline
\end{tabular}

* excludes people given orders under more than one legal category.

** excludes Breach of Probation and orders made in respect of children and young persons under $s 61$ of the 1959 Act.

*** from 1973 onwards, detailed information about non indictable offences has not been provided in the official statistics and the figures, particularly those for sexual and other categories of offence cannot, be compared for the periods before and after that year.

to 30 , the annual mean being 17.9 (s.d. 5.9). Female offender patients account for $11.5 \%$ of restricted orders annually (s.d. 4.4). This percentage is significantly smaller than the equivalent proportion for unrestricted orders which is $16.4 \%$ (s.d. 2.9) $(P<0.001)$ and probably reflects the criminal criteria used in making the order. The average proportion of females among those found guilty of an indictable offence in England and Wales is $14 \%$ (s.d. 1.0), a remarkably consistent statistic and midway between the ordinary hospital order and the restricted order proportions for female offender patients.

The number of males given restricted orders has varied considerably over the years, the mean being 161.4 (s.d. 57.8) and the range, 76 to 262 . Comparison with the total numbers found guilty of indictable offences during those years serves to highlight the very special nature of the restricted order population. The number of people found guilty of indictable crime in 1961 was 182,217 and this figure has risen more or less consistently since then, the number in 1985 being a little over 441,000 . The proportion of these people given a restricted hospital order in any one year is barely measurable, varying between $0.03 \%$ and $0.08 \%$.

\section{(d) By type of offence}

Details of the types of offence committed by restricted order patients are presented in Table I and Table III. Because of changes in the way certain categories of conviction have been grouped together over the years, it is possible to give only a rough outline of the types of offence involved and indeed, since 1982, such 
The restricted hospital order

TABLE III

Restricted order patients, 1961-1982: Type of offence by type of hospital

\begin{tabular}{lrrrr}
\hline & \multicolumn{4}{c}{ Type of hospital } \\
Special & \multicolumn{2}{c}{ local } \\
Offence & $n$ & $\%$ & $n$ & $\%$ \\
& & & & \\
\hline & 1249 & 73 & 463 & 27 \\
Violence against the person & 184 & 31 & 416 & 69 \\
Sex & 228 & 30 & 521 & 70 \\
Theft & 462 & 55 & 384 & 45 \\
Other & & & & \\
\hline
\end{tabular}

$\mathrm{X}^{2}=547.1$ d.f. $3 P<0.00001$

information has ceased to be publicly available. Within the restricted order population, there has been a consistent increase in the proportion of offences of violence against the person. This increase is independent of the actual number of orders made in this category; these increased until the early 1970s and declined after 1974. The proportional rise in violent offences is offset by decreases in orders for people found guilty of sex and theft offences, both of which reduced in number and proportional representation after 1973.

Given the criteria employed in the making of a restricted order, it is only to be expected that violent offences occur proportionately more frequently in the restricted than in the unrestricted populations (Tables I and II). In the unrestricted group, the mean annual number of violent offences is $17 \%$ (s.d. 5.6) and among the restricted population, the figure is $55 \%$ (s.d. 10.6) $(P<0.0001)$. Many of the offences of violence among people given unrestricted orders are of a very minor nature. For example, from 1961 to 1972 (after 1972 such information was not published), non indictable assaults accounted for, on average, $33 \%$ of the violent offences in the unrestricted group (s.d. 6.9). At the other end of the scale, homicide is rarely found among unrestricted patients, comprising only $4 \%(74 / 1720)$ of the violent offences recorded between 1961 and 1972, and of these 74 homicides, $50(67 \%)$ involved female offenders. In the restricted order population, homicide offences comprised $33 \%$ of violent offences over the same period.

There is a strong relationship between type of offence and the type of hospital to which the person was admitted (Table III). Homicide figures were presented separately in the relevant criminal statistics from 1961 until 1972, during which time 254 (81\%) of the 312 homicide offenders given a restricted hospital order were admitted to a special hospital. In the same period, of 594 people given restricted orders after being convicted of theft, $451(76 \%)$ were admitted to a local hospital. In 1961, the first full year of the 1959 Act's operation, local hospitals had admitted nine of the 12 homicide offenders who had been given restricted orders. This pattern was never to be repeated and, presumably, reflects a misunderstanding on the part of the judiciary regarding the degree of security available in local psychiatric hospitals (p 87). ${ }^{2}$ As already stated, 1973 was a turning point in the admissions pattern for both special and local hospitals. In the three years leading up to 1973 , local hospitals admitted 31 people who had been convicted of homicide or attempted homicide. In the years 1974-1976, the local hospital intake of such offenders comprised 12 people. Analysis beyond these years is not possible because homicide and all other offences of violence against the person were then placed into one category in the official statistics.

What is quite clear is that, in addition to the restrictions listed in the legislation, unstated rules have operated through the years in determining the type of hospital to which restricted patients should be sent. Those convicted of serious offences have been detained in maximum security for the most part.

\section{Legal aspects}

As Walker \& $\mathrm{McCabe}^{2}$ state, in the event of treatment needs being weighed in opposition to secure containment, the latter has taken precedence in the court's sentencing decisions and public safety has been regarded by the judiciary as of paramount importance. They quote a judgment in the case of $R$. $v$. Harvey and Ryan. The case concerned a woman who had killed, had been found guilty of manslaughter and had been accepted by Broadmoor hospital as a suitable potential patient. The judge reasoned, "It is tempting to (send her to hospital) but I don't think it is right. The hospital authorities may take the view that while she is a very evil, bad and dangerous person, they cannot continue to regard her as a person who is mentally sick and they may also take the view that they cannot do anything further to cure her. The pressure to deal with people who are more helpful and less evil might lead them to wish to discharge her, and she probably has some legal rights for consideration for discharge when it is supposed, without any guarantee, that she may be cured..." (p 88).

The judge need not have worried. Until the implementation of the 1983 MHA, the prospective patient would have required the Secretary of State's approval for discharge or transfer and, regardless of whether or not she might have been considered either cured or curable by her doctors, it would have been her potential dangerousness that would have been of consideration to the Home Office. The above judgment was made in 1971 and the judiciary have continued to send many mentally disordered offenders 
who have obtained notoriety to prison rather than to hospital.

Following a practice direction by Lord Chief Justice Parker in 1963, the great majority of restricted orders has been made without a time limit being stipulated. The direction was based on the judge's understanding of the nature of psychiatric treatment; 'since in most cases, the prognosis cannot be certain, the safer course is to make any restriction order unlimited in point of time. ${ }^{2}$ (p. 92). The statement assumes a causal link between illness and further offending, though such a link need not be established before a hospital order is made. If prognosis cannot be certain, it cannot be certain whatever the point in time at which it is made. It follows that the purpose in making an indefinite restricted order is to extend control over the doctor, not the patient; the principle indeed on which the order was based. In any case, for the restricted patient, getting well in the psychiatric sense is not automatically followed by discharge from hospital. The seriousness of the offence of which the person had been convicted may make those concerned with discharge look to other factors in determining when release should take place. ${ }^{8}$

In the first three years of the 1959 Act's operation, the setting of time limits to restricted orders had been popular. Time limited orders comprised $44 \%$ of orders in $1961,39 \%$ in 1962 and $35 \%$ in 1963 . The percentage fell to $21 \%$ in 1964 and, since 1968 , time limited orders have never comprised more than $10 \%$ of restricted orders in any year, (note though that no publicly available figures have been provided since 1982).

Greater use of time limited orders has been advocated by Ashworth \& Gostin ${ }^{9}$ who state, "There are grounds for arguing that special restrictions ought not to last longer than a period proportionate to the gravity of the offence for which they were imposed (...) at least unless the case meets the criteria which would justify the impostion of life imprisonment on a person not suffering from a treatable mental disorder". ( $p$ 224)

The proposal makes no distinction between special and local hospitals, and clearly, special hospital detention has very different implications for the patient's liberty than detention in a local psychiatric hospital. It also seeks to correct what is seen as an injustice by accepting in principle the idea that the restricted order is somehow equivalent to a prison sentence, thus placing the hospital to which the person is sent in the role of prison and the doctor in charge ot the case in the role of jailor or governor. This would not be acceptable to hospitals or doctors. The ending of restrictions does not cause a restricted patient to be discharged, rather it takes away from such a patient the benefits which might be conferred by conditional discharge. It might also adversely affect the patient's chances of release since the power to conditionally discharge is regarded positively by many doctors. ${ }^{10.11}$

As pointed out above, in the making of hospital orders, courts are not required to consider the relationship between a person's offence and his mental disorder. It is enough for the court to be presented with the evidence of two doctors regarding the nature of disorder present. In practice of course, a causal connection between offence and disorder is implicitly assumed by the court and often explicitly referred to by the reporting psychiatrists.

\section{Comment}

Insofar as it was conceived when mental hospitals were deemed to be secure institutions, the restricted hospital order, and indeed the hospital order on which it is based, are anachronisms. In the extent to which it purports to be concerned with the behaviour of the patient and not the doctor, the restricted order is misleading, and in consequence of the European Court's ruling in 1981, it no longer offers the Home Office effective control over dangerous patients, its original purpose.

The restricted order represents a compromise between, on the one hand, the need to detain securely those believed to be dangerous and on the other, the need to ensure that those who require psychiatric treatment receive it. In an imperfect world, it may be the best possible compromise that can be achieved between these two needs. However, the assumptions on which the hospital order itself is based are open to question. In the first place, the equation between hospital and prison made by the proposers of the hospital order is invalid and whether or not an offence is punishable by imprisonment should not have to be considered before a court can take the action of sending to hospital care. Second, the hospital order is a treatment order and the fact of the matter is that it is not meaningful for a court to sentence to treatment. In practical terms, courts can only send someone to hospital, not sentence them to stay there for any period of time, whether fixed or otherwise. They therefore require the power to place a person in the care of a psychiatric hospital but not the power to state or recommend how long that person remain there.

If these assumptions and powers were to be laid aside, it would, of course, follow that the restricted order in its present form would no longer be viable. Its survival, despite distinctly dubious psychiatric foundations, is due to the great benefits it affords lawyers, doctors and courts, namely its administrative tidiness and its flexibility.

The first of these qualities has been diminished somewhat by the 1981 ruling of the European court of Human Rights, which effectively forced the Government of the day to remove sole authority of discharge from the Home Secretary and give it also to 
special Mental Health Review Tribunals. Whereas the former need only consider public safety issues in relation to the person's discharge, tribunals are obliged to order a patient's absolute discharge if he is not suffering from a mental disorder which makes it appropriate for him to be detained in a hospital for medical treatment (see above). It was clearly the wish of the European Court of Human Rights that the restricted patient should have his detention tested against the criteria used to detain any other category of patient. In theory, this was achieved by restoring to him the right to be discharged by a Tribunal. However, as Peay has found ${ }^{12}$ public safety issues, and not the patient's mental state predominate when Tribunals have to consider the discharge of a restricted patient, and it is proposed here that, whatever procedural device may be introduced, the offence, and not the mental state of the individual will always be paramount in the considerations of any review body. It is misleading, and to some extent dishonest, to pretend otherwise, and it may be argued that apart from those who are unfit for trial or those for whom a defence of insanity could be offered, the preventive detention and treatment of mentally disordered offenders should be separated from one another in the sentencing deliberations of the Court.

To put such changes into effect, Courts would need to be able to use the hospital order (the ability to send someone to hospital) in combination with other types of disposal including imprisonment, so that, where appropriate, such disposals would be used in place of the restricted hospital order. However, at the same time, Courts would need to be given the power to order that aftercare provisions be made for those sent to hospital with or without an accompanying prison sentence. As we have seen, since its conception, the merits of the restricted order have been justified with reference to its aftercare provisions but there is no reason why these should be tied to the doctor's right to discharge patients.

\section{Acknowledgements}

I am very grateful to Susanne Dell, Maureen Bartholomew and the Home Office Statistics Division for help in the preparation of this paper.

\section{References}

${ }^{1}$ Royal Commission (1957) Royal Commission on the Law relating to Mental Illness and Mental Deficiency. Cmnd. 169. London: HMSO.

${ }^{2}$ WALKER, N. \& MCCABE, S. (1973) Crime and Insanity in England Vol. 2. Edinburgh University Press: Edinburgh.

${ }^{3}$ Robertson, G. (1982) The 1959 mental health act of England and Wales: Changes in the use of its criminal provisions. In Abnormal Offenders, Delinquency and the Criminal Justice System (eds. J. Gunn \& D. P. Farrington). Chichester: Wiley.

${ }^{4}$ DHSS, HOME OFFICE (1986) Offenders Suffering from Psychopathic Disorder. Crown copyright.

${ }^{5}$ DHSS, Home OfFice, Welsh Office, LoRd ChancelLOR'S DEPARTMENT (1978) Review of the Mental Health Act 1959. Cmnd. 7320. London: HMSO.

${ }^{6}$ Prins, H. (1980) Offenders, Deviants or Patients? London: Tavistock.

${ }^{7}$ Rollin, H. R. (1969) The Mentally Abnormal Offender and the Law. Pergamon Press: Oxford.

${ }^{8}$ Dell, S. \& Rober tson, G. (1988) Sentenced to Hospital. Oxford: Oxford University Press.

${ }^{9}$ AsHWORTH, A. \& Gostin, L. (1985) Mentally disordered offenders and the sentencing process. In Secure Provision (ed. L. Gostin). London: Tavistock.

${ }^{10}$ Home OFFICE, DHSS (1975) Report of the Committee on Mentally Abnormal Offenders (Butler Committee report) Cmnd. 6244. London: HMSO.

${ }^{11}$ TidMarsh, D, (1981) Letter, Bulletin of the Royal College of Psychiatrists, 5, 211.

${ }^{12}$ PeAY, J. (1981) Mental Health Review Tribunals after the Mental Health Act 1983, Unpublished Report to DHSS. 